Article

\title{
Designing Phenyl Porous Organic Polymers with High-Efficiency Tetracycline Adsorption Capacity and Wide pH Adaptability
}

\author{
Wenjie Nie ${ }^{1, *}$, Jiao Liu ${ }^{1}$, Xue Bai ${ }^{1}$, Zefeng Xing $^{1}$ and Ying Gao ${ }^{2, *}$ \\ 1 College of Geology and Environment, Xi'an University of Science and Technology, Xi'an 710054, China; \\ LJ1379885898@126.com (J.L.); baixue@shu.edu.cn (X.B.); 18409050128@stu.xust.edu.cn (Z.X.) \\ 2 Department of Teaching Quality Evaluation, Yan'an University, Yan'an 716000, China \\ * Correspondence: nwj@xust.edu.cn (W.N.); yadxgy@yau.edu.cn (Y.G.)
}

Citation: Nie, W.; Liu, J.; Bai, X.; Xing, Z.; Gao, Y. Designing Phenyl Porous Organic Polymers with

High-Efficiency Tetracycline

Adsorption Capacity and Wide $\mathrm{pH}$

Adaptability. Polymers 2022, 14, 203

https://doi.org/10.3390/

polym14010203

Academic Editor: Shin-ichi Yusa

Received: 8 October 2021

Accepted: 10 November 2021

Published: 5 January 2022

Publisher's Note: MDPI stays neutral with regard to jurisdictional claims in published maps and institutional affiliations.

Copyright: (C) 2022 by the authors. Licensee MDPI, Basel, Switzerland. This article is an open access article distributed under the terms and conditions of the Creative Commons Attribution (CC BY) license (https:// creativecommons.org/licenses/by/ $4.0 /)$

\begin{abstract}
Adsorption is an effective method to remove tetracycline (TC) from water, and developing efficient and environment-friendly adsorbents is an interesting topic. Herein, a series of novel phenyl porous organic polymers (P-POPs), synthesized by one-pot polymerization of different ratios of biphenyl and triphenylbenzene under $\mathrm{AlCl}_{3}$ catalysis in $\mathrm{CH}_{2} \mathrm{Cl}_{2}$, was studied as a highly efficient adsorbent to removal of TC in water. Notably, the obtained POPs possessed abundant phenylcontaining functional groups, large specific surface area $\left(1098 \mathrm{~m}^{2} / \mathrm{g}\right)$ with abundant microporous structure, high pore volume $\left(0.579 \mathrm{~cm}^{3} / \mathrm{g}\right)$, favoring the removal of TC molecules. The maximum adsorption capacity (fitted by the Sips model) could achieve $581 \mathrm{mg} / \mathrm{g}$, and the adsorption equilibrium is completed quickly within $1 \mathrm{~h}$ while obtaining excellent removal efficiency (98\%). The TC adsorption process obeyed pseudo-second-order kinetics and fitted the Sips adsorption model well. Moreover, the adsorption of POPs to TC exhibited a wide range of $\mathrm{pH}(2-10)$ adaptability and outstanding reusability, which could be reused at least 5 times without significant changes in structure and efficiency. These results lay a theoretical foundation for the application of porous organic polymer adsorbents in antibiotic wastewater treatment.
\end{abstract}

Keywords: adsorption; porous organic polymers; tetracycline; $\mathrm{pH}$ adaptability; reusability

\section{Introduction}

The soaring usage of antibiotics in recent years has resulted in their widespread presence in water [1]. In particular, tetracycline (TC), as an essential antibiotic, accomplishes sterilization by inhibiting the synthesis of microbial proteins such as gram bacteria and chlamydia to control and treat diseases, and is extensively used in medication, cattle farming, and other fields due to its particular advantages, such as broad spectrum, low toxicity, low cost, and so on [2,3]. However, $30-90 \%$ of TC ingested by humans and animals is released into the aquatic environment together with excrement which is difficult to decompose [4,5]. Notably, the long-standing accumulation of TC in the environment could induce the production of bacterial resistance and even lead to the transfer of resistance genes, which further causes some serious ecological and health risk [6]. Therefore, the development of an effective method to remove TC from water circumstance is urgently necessary.

In recent decades, various methods including ion-exchange [7], membrane separation [8], chemical oxidation [9], photodegradation [10,11], adsorption [12-15] and other technologies [16-18] have been employed to treat TC pollution in water. Among above methods, the adsorption is widely used in the field of TC wastewater treatment due to its advantages such as simple operation, low price, random reaction conditions, no significant changes in active sites and spatial structure after adsorption, and reusability of absorbents [19-21]. More importantly, for adsorption, the efficiency and practical feasibility are extremely dependent on the type and nature of the adsorbent. To date, the existing 
adsorption materials used for the removal of TC include: clay [22], graphene oxide [23], activated carbon [24], metal organic framework compounds [25], and so on [26,27]. However, the development of excellent performance adsorbents is still challenging for TC removal, since the previously reported materials have certain disadvantages, such as lengthy procedures of preparation, weak selective adsorption capacity for TC, low adsorption rate, limited narrow $\mathrm{pH}$ rang, and difficulty in regeneration.

Surprisingly, due to the high porosity, large specific surface area, excellent stability, and pore structure adjustability through the introduction of specific functional groups, porous organic polymers as an advanced porous material are gaining widespread attention [28-30]. In recent years, the research on adsorbent-based porous organic polymers (POPs) has come to prominence because of their unique adsorption properties for antibiotics in water. For example, in 2018, Liu [31] et al. devised and synthesized diol-based porous organic polymers for the first time as absorbents for TC removal, and mechanism research showed that the multidentate hydroxyl groups of diol-based porous organic polymers ensured high binding energy to TC species. However, the maximum adsorption capacity was only $155.8 \mathrm{mg} / \mathrm{g}$ and it taken up to $300 \mathrm{~min}$ to reach adsorption equilibrium, and the high adsorption performance was limited to the $\mathrm{pH} \mathrm{8-10} \mathrm{of} \mathrm{the} \mathrm{solution.} \mathrm{Further} \mathrm{development} \mathrm{of} \mathrm{porous}$ organic polymers with high efficiency and conditional universality to improve the removal performance for TC is worth looking forward to. Then, Song [32] and co-workers developed conjugated microporous polymers via the Pd-catalyzed Suzuki coupling reactions of 2,4,6-tris(4-bromophenyl) pyridine with two aromatic borates and obtained excellent adsorption efficiency using it for the adsorption of TC in aqueous solution. Unfortunately, although the adsorption equilibrium in this process could be reached within $1 \mathrm{~h}$ and the maximum adsorption capacity of the material was as high as $909.09 \mathrm{mg} / \mathrm{g}$, the addition of organic solvents to adjust the dispersibility of the adsorbent in water and the environmental risk of heavy metals to aquatic plants remains a challenge. Moreover, the reusability of the CMP materials still needs further exploration. Therefore, it is still pressing to design and fabricate specific, efficient, wide range of $\mathrm{pH}$ adaptability, environment-friendly, and recyclable POPs as adsorbents to remove TC pollution in water.

Herein, we used biphenyl and triphenylbenzene as feedstock to synthesize four kinds of phenyl porous organic polymers (P-POPs) as adsorbents to remove TC in water. In addition, the structure and property of the obtained P-POPs were characterized and analyzed by scanning electron microscopy (SEM), Brunauer-Emmett-Teller (BET), Fourier transform infrared spectroscopy (FT-IR), Thermogravimetric analysis (TGA), zeta potential analyzer, and so on. Furthermore, the affecting factors, adsorption kinetics, and adsorption isotherms of TC adsorption were systematically investigated. The stability and reusability of P-POPs were also evaluated. The optimized P-POPs was possessed high TC adsorption amount of $581 \mathrm{mg} / \mathrm{g}$, fast adsorption kinetics (about $1 \mathrm{~h}$ of adsorption equilibrium time), wide range of $\mathrm{pH}$ adaptability (no significant difference in TC adsorption capacity in $\mathrm{pH}$ 2-10 range), excellent recyclability (be reused at least 5 times without significant changes in their structure), good dispersion performance in aqueous solutions and no need for organic solvents. This work is significant to the exploration of new adsorbents, and provides certain theoretical support for the adsorption of porous organic polymers (POPs) to eliminate antibiotic pollution.

\section{Materials and Methods}

\subsection{Chemical Reagents}

The materials used in this work are all analytically pure (AR), and unless otherwise specified, they will not be processed and used directly. Biphenyl (99\%), triphenylbenzene $(98 \%)$ and anhydrous aluminum trichloride $(99 \%)$ were purchased from Saen Chemical Technology Co., Ltd. (Shanghai, China). Dichloromethane, methanol, and tetrahydrofuran were supplied by Shanxi Tongjie Chemical Reagent Co., Ltd. (Shanxi, China). Sodium hydroxide was purchased from Guangdong Guanghua Sci-Tech Co., Ltd. (Guangdong, China). 


\subsection{Typical Procedure for the Synthesis of P-POPs}

Four P-POPs were prepared on the basis of the previous reports with certain adjustments, and the typical synthetic pathway was illustrated in Scheme 1 [30]. Four kinds of P-POPs were synthesized from biphenyl and triphenylbenzene in different molar ratios (biphenyl:triphenylbenzene $=1: 2,1: 1,2: 1,3: 1$, respectively) as monomers, and they were sequentially expressed as P-POPs- $\mathrm{x}(\mathrm{x}=1 \sim 4)$. Taking the preparation of P-POPs-1 samples as an instance, the reaction was run in a $100 \mathrm{~mL}$ double-necked flask equipped with a condenser under the protection of nitrogen. First, anhydrous aluminum trichloride (1.06 g) was added into the reactor containing $60 \mathrm{~mL}$ of dichloromethane and stirred for $1 \mathrm{~h}$; then $77 \mathrm{mg}$ of biphenyl $(0.5 \mathrm{mmol})$ and $306 \mathrm{mg}$ of triphenylbenzene $(1 \mathrm{mmol})$ were quickly added to the reaction flask, and immediate discoloration was observed. After refluxing at $70{ }^{\circ} \mathrm{C}$ for $16 \mathrm{~h}$, the mixture was filtered and washed with methanol/dilute hydrochloric acid (1:1 volume ratio) three times to removed possible residual aluminum trichloride. Afterwards, the product was further refluxed and washed for $48 \mathrm{~h}$ through Soxhlet extractor with tetrahydrofuran/Methanol/water (1:1:1 volume ratio). Finally, the P-POPs-1 polymer material was obtained by vacuum drying at $130{ }^{\circ} \mathrm{C}$ for $12 \mathrm{~h}$ [30].

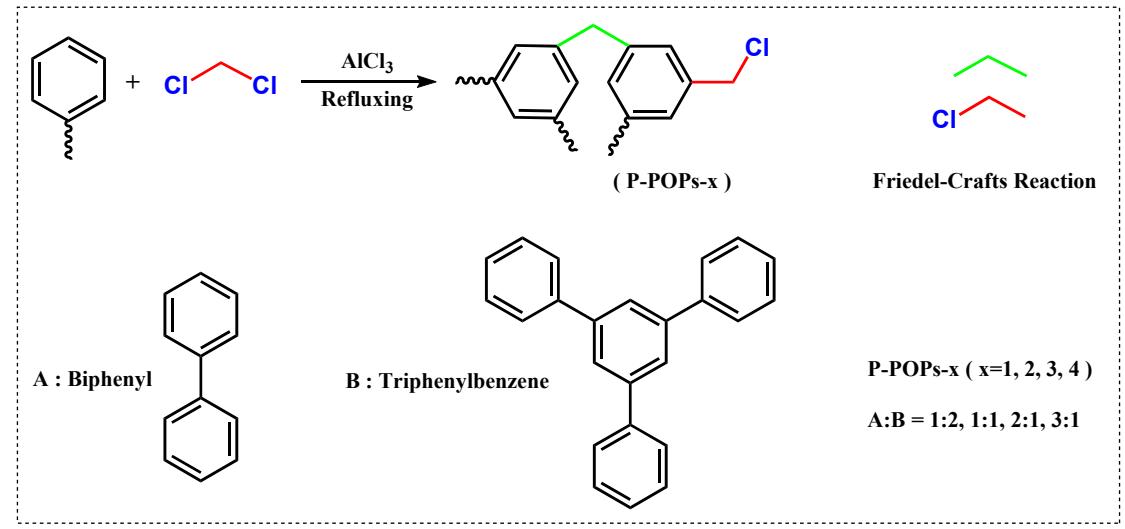

Scheme 1. The synthesis route of phenyl porous organic polymers (P-POPs).

\subsection{Characterization of Samples}

The surface morphologies of P-POPs were recorded by scanning electron microscopy (SEM, JSM-7610F, Electronics Corporation, Tokyo, Japan). The specific surface area and pore-size distribution of the P-POPs were evaluated based on the Brunauer-Emmett-Teller method (BET, Micromeritics, Atlanta, GA, USA). The determination of the chemical structure was done by Fourier transform infrared spectroscopy (FT-IR, TENSOR 27, Bruker, Karlsruhe, Germany). The thermal stability of the materials was detected by thermogravimetric analysis (TGA, STA PT1600, Linseis, Bavaria, Germany). The surface potential values of P-POPs-3 were measured by zeta potential analyzer (Malvern Instrument Co., Malvern, UK).

\subsection{Adsorption Experiment}

All experiments were carried out to explore the adsorption performance of P-POPs at $25^{\circ} \mathrm{C}$. The $40 \mathrm{~mL}$ of $50 \mathrm{mg} / \mathrm{L} \mathrm{TC}$ solution was added into the centrifuge tube containing $0.01 \times g$ P-POPs. Then the centrifuge tube was placed in a gas bath to shake for $7 \mathrm{~h}$ at $150 \mathrm{rpm}$ under dark to ensure adsorption equilibrium. After adsorption, the concentrations of residual TC in the filtrate were detected by an UV-vis spectrophotometer (UV 2600, Shmadezu, Japan, $\lambda=356 \mathrm{~nm}$ ). All the adsorption experiments were conducted in triplicates. In addition, target uptake at equilibrium $\left(\mathrm{q}_{\mathrm{e}}, \mathrm{mg} / \mathrm{g}\right)$ and corresponding removal rate $\left(\mathrm{R}_{\mathrm{r}}\right.$, $\%$ ) were obtained from the follow Equations (1) and (2), successively:

$$
\mathrm{q}_{\mathrm{e}}=\frac{\left(\mathrm{C}_{0}-\mathrm{C}_{\mathrm{e}}\right) \mathrm{V}}{\mathrm{m}}
$$




$$
\mathrm{R}_{\mathrm{r}}=\frac{\mathrm{C}_{0}-\mathrm{C}_{\mathrm{e}}}{\mathrm{C}_{0}} \times 100 \%
$$

where $C_{0}(\mathrm{mg} / \mathrm{L})$ and $\mathrm{C}_{e}$ are the initial and equilibrium concentration of TC. V $(\mathrm{L})$ means the volume of TC solution and $\mathrm{m}(\mathrm{g})$ represents the P-POPs dosage.

To study the adsorption kinetics, the adsorption process was carried out using $50 \mathrm{mg} / \mathrm{L}$ TC solution at a time interval of 5-420 min. The equations of pseudo-first- and pseudosecond-order kinetics are expressed as follows Equations (3) and (4):

$$
\begin{gathered}
\ln \left(\mathrm{q}_{\mathrm{e}}-\mathrm{q}_{\mathrm{t}}\right)=\ln \mathrm{q}_{\mathrm{e}}-\mathrm{k}_{1} \mathrm{t} \\
\frac{\mathrm{t}}{\mathrm{q}_{\mathrm{t}}}=\frac{1}{\mathrm{k}_{2} \mathrm{q}_{\mathrm{e}}^{2}}+\frac{\mathrm{t}}{\mathrm{q}_{\mathrm{e}}}
\end{gathered}
$$

where $\mathrm{q}_{\mathrm{t}}$ and $\mathrm{q}_{\mathrm{e}}(\mathrm{mg} / \mathrm{g})$ are the quantity of TC adsorbed onto P-POPs at time $\mathrm{t}$ and at equilibrium (min), successively, and $\mathrm{k}_{1}(1 / \mathrm{min})$ and $\mathrm{k}_{2}(\mathrm{~g} /(\mathrm{mg} \cdot \mathrm{min}))$ are the rate constants of the pseudo-first-order adsorption process and pseudo-second-order adsorption process, successively.

To investigate the effect of adsorbent dosage and solution $\mathrm{pH}$, the dosage of P-POPs-3, the optimal material previously screened out, was varied in the range of $4-20 \mathrm{mg}$, and the $\mathrm{pH}$ value of TC solution increased from 2 to 12 under the adjustment of $0.01 \mathrm{~mol} / \mathrm{L} \mathrm{HCl}$ and $\mathrm{NaOH}$.

The adsorption isotherm was investigated through varying the initial concentration of TC solution from 10 to $270 \mathrm{mg} / \mathrm{L}$. The Langmuir, Freundlich, and Sips equations were used to fit the experimental data. In addition, the Langmuir isotherms Equation (5), the Freundlich isotherms Equation (6) and Sips isotherms Equation (7) are as follows:

$$
\begin{gathered}
\mathrm{q}_{\mathrm{e}}=\frac{\mathrm{q}_{\mathrm{m}} \mathrm{k}_{\mathrm{L}} \mathrm{C}_{\mathrm{e}}}{1+\mathrm{k}_{\mathrm{L}} \mathrm{C}_{\mathrm{e}}} \\
\mathrm{q}_{\mathrm{e}}=\mathrm{k}_{\mathrm{F}} \mathrm{C}_{\mathrm{e}}^{\mathrm{n}} \\
\mathrm{q}_{\mathrm{e}}=\frac{\mathrm{q}_{\mathrm{e}}\left(\mathrm{bC}_{\mathrm{e}}\right)^{1 / \mathrm{n}}}{1+\left(\mathrm{bC}_{\mathrm{e}}\right)^{1 / \mathrm{n}}}
\end{gathered}
$$

where $\mathrm{q}_{\mathrm{e}}(\mathrm{mg} / \mathrm{g})$ is the amounts of TC adsorbed at equilibrium, $\mathrm{C}_{\mathrm{e}}(\mathrm{mg} / \mathrm{L})$ is the equilibrium concentration of TC onto the adsorbent; $\mathrm{q}_{\mathrm{m}}(\mathrm{mg} / \mathrm{g})$ is the maximum monolayer adsorption, $\mathrm{k}_{\mathrm{L}}$ is Langmuir adsorption constant; $\mathrm{k}_{\mathrm{F}}$ is Freundlich constant representing for adsorption capacity and $n$ is the heterogeneity factor; $1 / n$ is also the heterogeneity factor and its close to 1 means the relatively uniform surface of the adsorbent, $b(\mathrm{~L} / \mathrm{mg})$ represents the median association constant.

In addition, the adsorbed P-POPs-3 was desorbed and regenerated using $50 \mathrm{~mL}$ $0.2 \mathrm{M} \mathrm{NaOH}$ as the eluent to desorb and regenerate $10 \mathrm{mg}$ of TC-adsorbed P-POPs-3 under ultrasonic conditions for $30 \mathrm{~min}$, and finally dry at $130^{\circ} \mathrm{C}$ for $12 \mathrm{~h}$ [33]. Then, the regenerated P-POPs-3 was used as adsorbent and recycled at $25^{\circ} \mathrm{C}$. The cyclic adsorptiondesorption test was run continuously for 5 times. In addition, the obtained desorption rates of the first to fifth cycles were $92 \%, 90 \%, 89 \%, 90 \%$, and $87 \%$, respectively.

\section{Results and Discussion}

\subsection{Structural Analysis and Characterization of Material}

The FT-IR analysis of P-POPs is shown in Figure 1. The adsorption peak appeared at $1460-1650 \mathrm{~cm}^{-1}$ reveals the existence of the benzene ring structure. The obvious bond at $2810-3010 \mathrm{~cm}^{-1}$ was corresponding to the absorption peak of $\mathrm{C}-\mathrm{H}$, which could be attributed to the stretching vibration of the methylene group $\left(-\mathrm{CH}_{2}-\right)$. This results indicated that the four kinds of P-POPs synthesized by Friedel-Crafts reaction between the raw materials and dichloromethane, which were consistent with the previous reports $[30,34]$. 


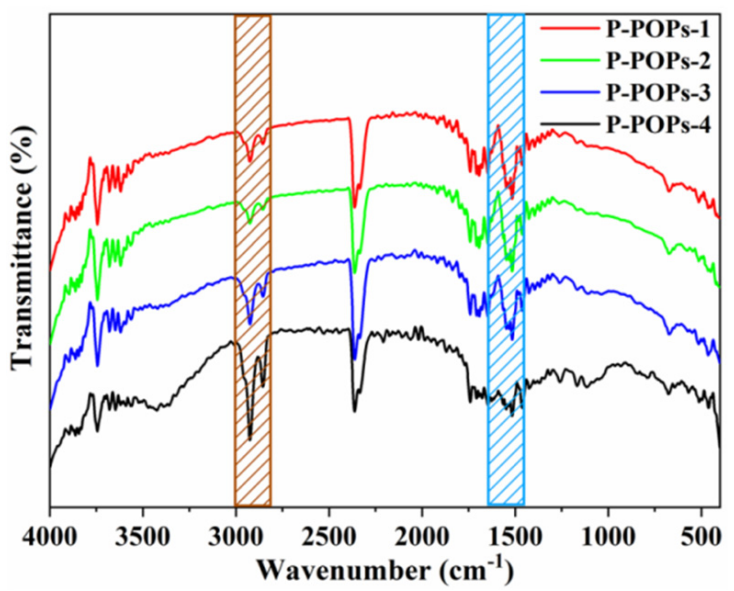

Figure 1. FT-IR spectrum of P-POPs-1, P-POPs-2, P-POPs-3, P-POPs-4.

The synthesized P-POPs samples were insoluble in a series of common organic solvents such as dichloromethane, methanol, ethanol, ethyl acetate and tetrahydrofuran, indicating their high chemical stability. Moreover, to prove the thermostability of P-POPs, thermogravimetric analysis (TGA) curves are shown in Figure 2. A slight weight loss of about $15 \sim 30 \%$ from 0 to $200{ }^{\circ} \mathrm{C}$ for P-POPs, which may be corresponded to the loss of residual solvent in the polymers or the escape of adsorbed water vapor [35]. At around $330^{\circ} \mathrm{C}$, the weight increases on the thermogravimetric curve possibly due to a small amount of aluminum resulting from the $\mathrm{AlCl}_{3}$ catalyst remained in the polymers, which may be converted into $\mathrm{Al}_{2} \mathrm{O}_{3}$ or other $\mathrm{Al}$ oxides after burning in the air. Importantly, P-POPs had no significant degradation below $330^{\circ} \mathrm{C}$ and the dramatic weight loss was about $450{ }^{\circ} \mathrm{C}$, which indicated their high thermal stability.

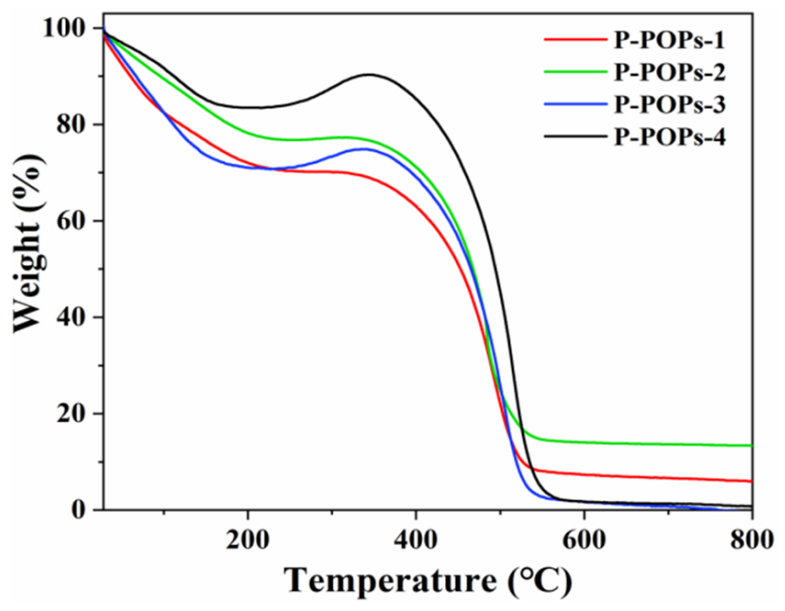

Figure 2. Thermogravimetric analysis of P-POPs under air.

The different morphologies of P-POPs were observed by a scanning electron microscope (Figure 3). P-POPs-1 and P-POPs-4 were comprised of a detached-spherical morphology, while P-POPs-2 and P-POPs-3 were comprised of a fused-spherical morphology. In addition, the average diameters of P-POPs computed by NanoMesurer software were $0.39,4.68,0.48$, and $1.54 \mu \mathrm{m}$, respectively. 

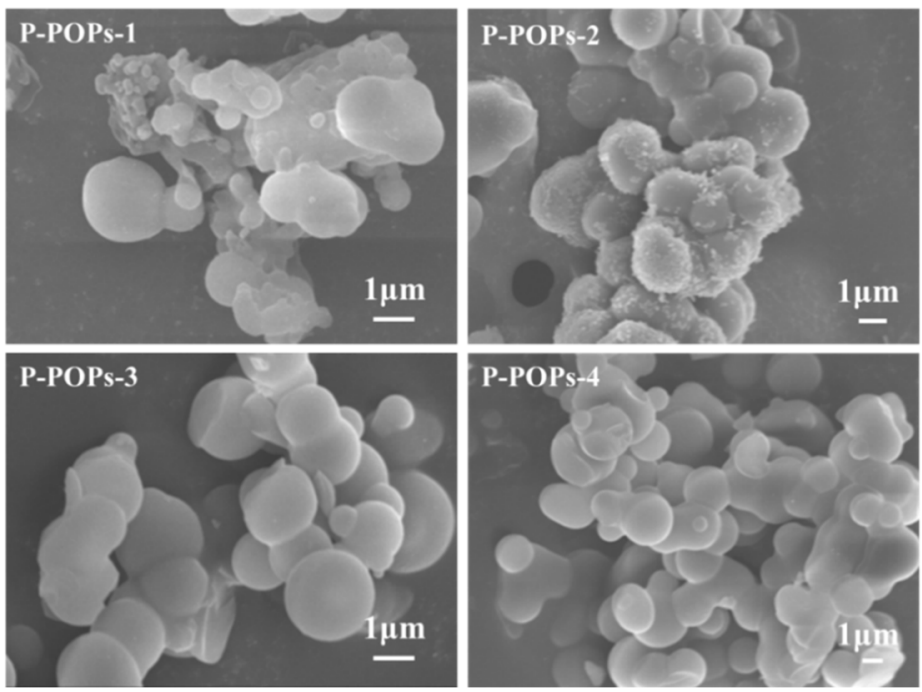

Figure 3. The SEM images of P-POPs.

Figure 4a showed the $\mathrm{N}_{2}$ adsorption and desorption isotherms of P-POPs at $77 \mathrm{~K}$. It was clear that all the four P-POPs exhibited type I sorption isotherms, which was one of the main characteristics of microporous materials. The non-occlusive nature of the adsorption/desorption isotherm may be due to the expansion of the polymer matrix, which was common in porous polymer. In addition, the porosity properties of P-POPs are listed in Table 1, their BET specific areas calculated from adsorption data were 571, 580, $1098,908 \mathrm{~m}^{2} / \mathrm{g}$ for P-POPs-1, P-POPs-2, P-POPs-3, P-POPs-4, respectively. Clearly, the synthesized P-POPs had excellent specific surface area, and the highest P-POPs-3 reached $1098 \mathrm{~m}^{2} / \mathrm{g}$, indicating that the use of biphenyl and triphenylbenzene as raw materials was beneficial to the synthesis of organic polymer materials with higher specific surface area, and the ratio of biphenyl with triphenylbenzene is an important factor affecting the specific surface area of the polymer. Moreover, P-POPs-3 possess the largest pore volume and median pore size, which are indispensable factors leading to its excellent adsorption performance. On the other hand, the pore-size distribution of P-POPs were displayed in Figure $4 \mathrm{~b}$. The pore width of P-POPs were mainly concentrated in the microporous area, which contributed to the excellent adsorption performance for TC, since the total molecule length of TC is $1.27 \mathrm{~nm}$ [21].
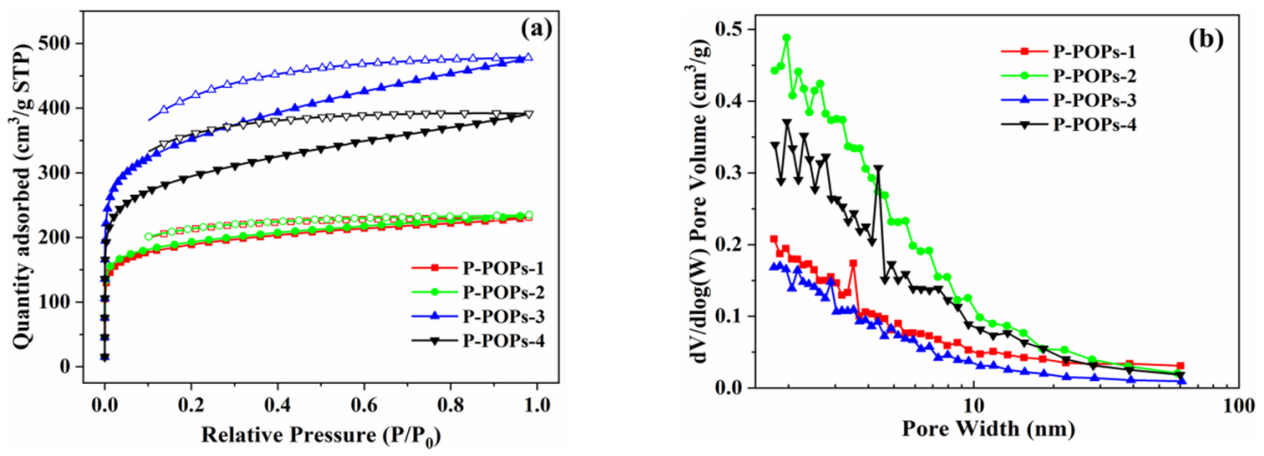

Figure 4. (a) $\mathrm{N}_{2}$ adsorption-desorption isotherms measured at $77 \mathrm{~K}$ and (b) pore-size distribution curves for P-POPs. 
Table 1. Information on the surface areas, pore volumes, and median pore diameter of P-POPs.

\begin{tabular}{cccc}
\hline Sample & $\mathbf{S}_{\text {BET }}\left(\mathbf{m}^{\mathbf{2}} / \mathbf{g}\right)$ & $\mathbf{V}_{\text {max }}\left(\mathbf{c m}^{\mathbf{3}} / \mathbf{g}\right)$ & $\mathbf{W}_{\text {med }} / \mathbf{n m}$ \\
\hline P-POPs-1 & 571 & 0.305 & 0.678 \\
P-POPs-2 & 580 & 0.311 & 0.637 \\
P-POPs-3 & 1098 & 0.579 & 0.698 \\
P-POPs-4 & 908 & 0.481 & 0.685 \\
\hline
\end{tabular}

\subsection{Effect of Adsorbent}

The TC removal performance of different P-POPs were evaluated by adding $10 \mathrm{mg}$ of absorbents to $40 \mathrm{~mL}$ of $50 \mathrm{mg} / \mathrm{L}$ TC aqueous solution (Figure $5 \mathrm{a}$ ). In the first $20 \mathrm{~s}$, the adsorption amount of TC by the four P-POPs increased rapidly with time, and then gradually flattened until the adsorption equilibrium. Notably, with the same initial concentration, the adsorption capacities of P-POPs for TC were in the sequence of P-POPs-3 $(196 \mathrm{mg} / \mathrm{g})>$ P-POPs-4 (195 mg/g) > P-POPs-2 (174 mg/g) > P-POPs-1 (170 mg/g). It can be concluded that the highest TC adsorption capacity $(196 \mathrm{mg} / \mathrm{g}$ ) was observed via P-POPs-3, which was consistent with the results on the specific surface area. This phenomenon indicated that the specific surface area is important factor affecting the adsorption performance of P-POPs. Then, P-POPs-3 was selected as the optimal materials to optimize the number of absorbents, and the influence of the amount of absorbent on the adsorption effect in the range of 4-20 $\mathrm{mg}$ was studied (Figure $5 \mathrm{~b}$ ). When the dosage of P-POPs was in the range of $4 \mathrm{mg}$ to $10 \mathrm{mg}$, the removal rate of TC was positively correlated with the amount of adsorbent. This was because the increase in the amount of adsorbent in the solution enhanced the collision probability of P-POPs particles with TC molecules, therefore improving its adsorption efficiency of TC in the aqueous solution. However, when the amount of adsorbent was further increased, the removal efficiency did not change significantly. Therefore, $10 \mathrm{mg}$ of adsorbent was selected for subsequent experiments, and the corresponding removal rate was $98 \%$. On the other hand, the adsorption capacity was negatively correlated with the amount of adsorbent, which may be caused by the discordant ratio between the number of TC molecules and the vacant sites of the P-POPs.
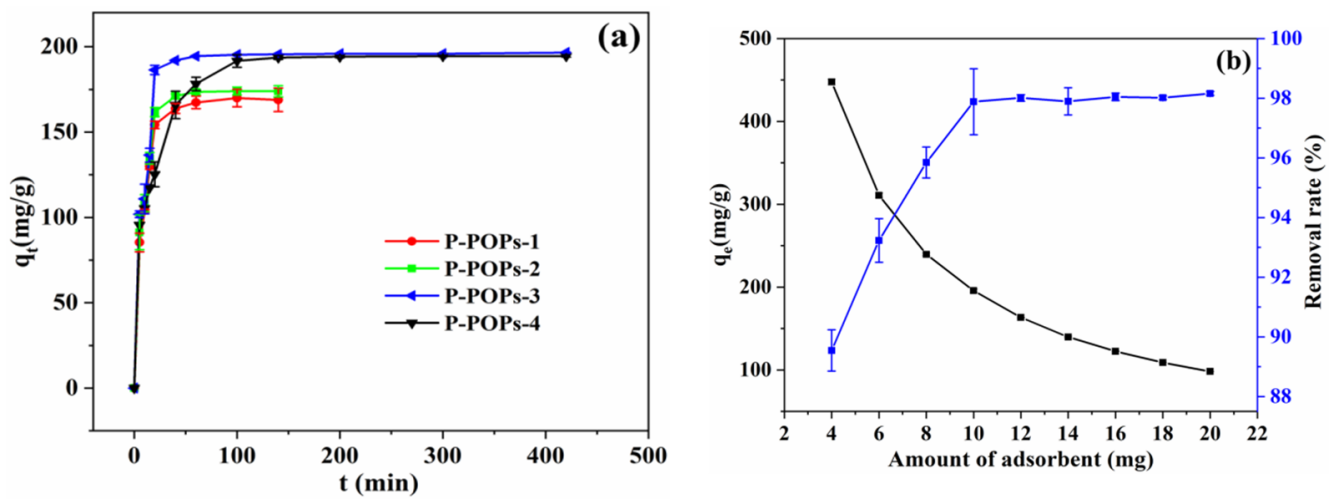

Figure 5. (a) The influence of adsorbent type and (b) dosage.

\subsection{Adsorption Kinetics}

Here, the adsorption kinetics of TC on P-POPs were illustrated in Figure 6. It was found that the TC adsorption was soared in the first $40 \mathrm{~min}$, which may be due to abundant adsorption sites and pores. Then, with the saturation of TC on the surface of the adsorbent and its active sites, the adsorption capacity increased slowly and reached equilibrium in about $60 \mathrm{~min}$. Two widely used kinetic models, namely pseudo-first-order and pseudosecond-order kinetics, were applied to evaluate the adsorption kinetics. Notably, the fitting curve generated by the pseudo-second-order kinetic model could describe the experimental data more closely and present a higher $\mathrm{R}^{2}$ value (0.999) (Table 2). On the other hand, the $\mathrm{q}_{\max }$ of the pseudo-second-order kinetic model was closer to the experimental data $\left(\mathrm{q}_{\exp }\right)$ 
(Table 2). Thus, the adsorption of TC by P-POPs obeyed pseudo-second-order kinetics, which indicated that chemical adsorption was the main adsorption mechanism.
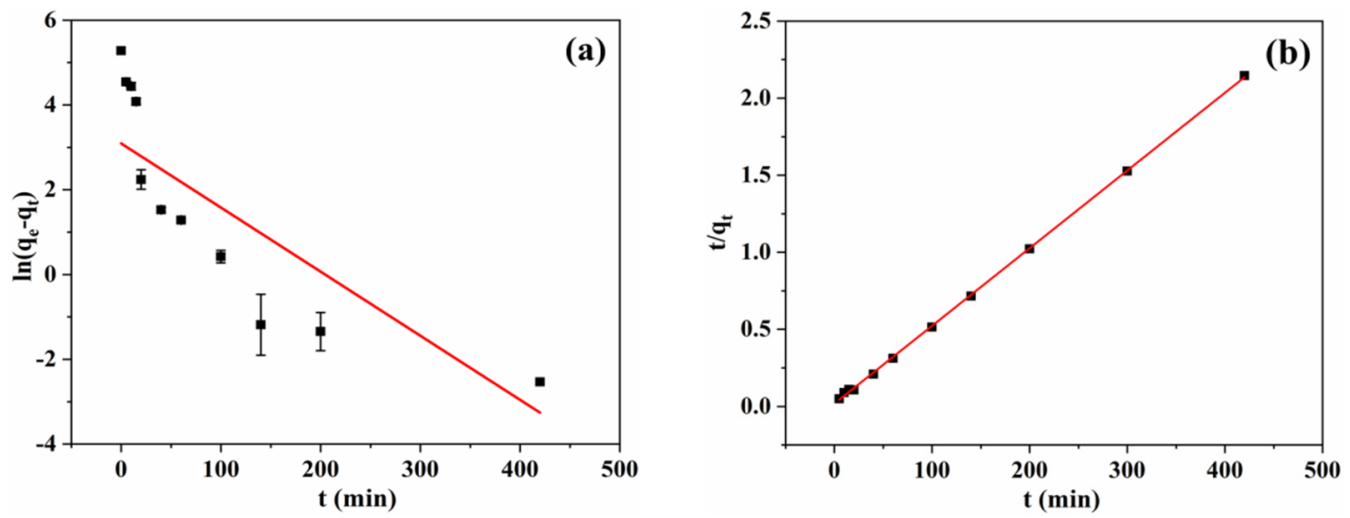

Figure 6. The fitted kinetics curves for TC adsorption onto P-POPs-3 by (a) pseudo-first-order model and (b) pseudo-second-order model.

Table 2. Kinetic parameters for the pseudo-first-order kinetic model and pseudo-second-order kinetic model.

\begin{tabular}{ccccccc}
\hline \multirow{2}{*}{$\begin{array}{c}\mathbf{q}_{\exp } \\
\mathbf{m g} / \mathbf{g})\end{array}$} & \multicolumn{3}{c}{ Pseudo-First-Order } & \multicolumn{3}{c}{ Pseudo-Second-Order } \\
\cline { 2 - 7 } & $\mathbf{k}_{\mathbf{1}}(\mathbf{1} / \mathbf{m i n})$ & $\begin{array}{c}\mathbf{q}_{\max } \\
(\mathbf{m g} / \mathbf{g})\end{array}$ & $\mathbf{R}^{\mathbf{2}}$ & $\begin{array}{c}\mathbf{k}_{\mathbf{2}} \\
(\mathbf{g} /(\mathbf{m g} \cdot \mathbf{m i n}))\end{array}$ & $\begin{array}{c}\mathbf{q}_{\max } \\
(\mathbf{m g} / \mathbf{g})\end{array}$ & $\mathbf{R}^{\mathbf{2}}$ \\
\hline 196 & 0.01512 & 9.0 & 0.639 & 0.0014 & 198.4 & 0.999 \\
\hline
\end{tabular}

\subsection{Adsorption Isotherms}

As shown in Figure 7, the effect of TC mass concentration on the adsorption capacity was investigated by adding $10 \mathrm{mg}$ P-POPs to $10 \sim 270 \mathrm{mg} / \mathrm{L} \mathrm{TC}$ solution. When the initial concentration of TC increased from $10 \mathrm{mg} / \mathrm{L}$ to $170 \mathrm{mg} / \mathrm{L}$, the adsorption capacity of TC on P-POPs enhanced rapidly, and then, the growth rate decreased and tended to balance. The adsorption behavior of TC onto P-POPs was assessed by the Langmuir, Freundlich and Sips isotherm models, and the correlation coefficients $\left(R^{2}\right)$ were $0.9829,0.9078$ and 0.9850 , respectively (Table 3 ). The results showed that the Sips model had a higher $\mathrm{R}^{2}$ value and the theoretical maximum adsorption capacities $(581 \mathrm{mg} / \mathrm{g})$ calculated from Sips model were approximated to the experimental date $(581 \mathrm{mg} / \mathrm{g}$ ) (Table 3). In addition, the value of $1 / \mathrm{n}$ obtained by the Sips fitting was close to 1 , indicating that the surface of the adsorbent was relatively uniform, and the Sips isotherm was close to the Langmuir equation, which was consistent with the fitting results in the figure. On the other hand, the $1 / \mathrm{n}$ value obtained in the Freundlich model is less than 1.0, indicating that the adsorbent was beneficial to remove TC from the aqueous solution. 


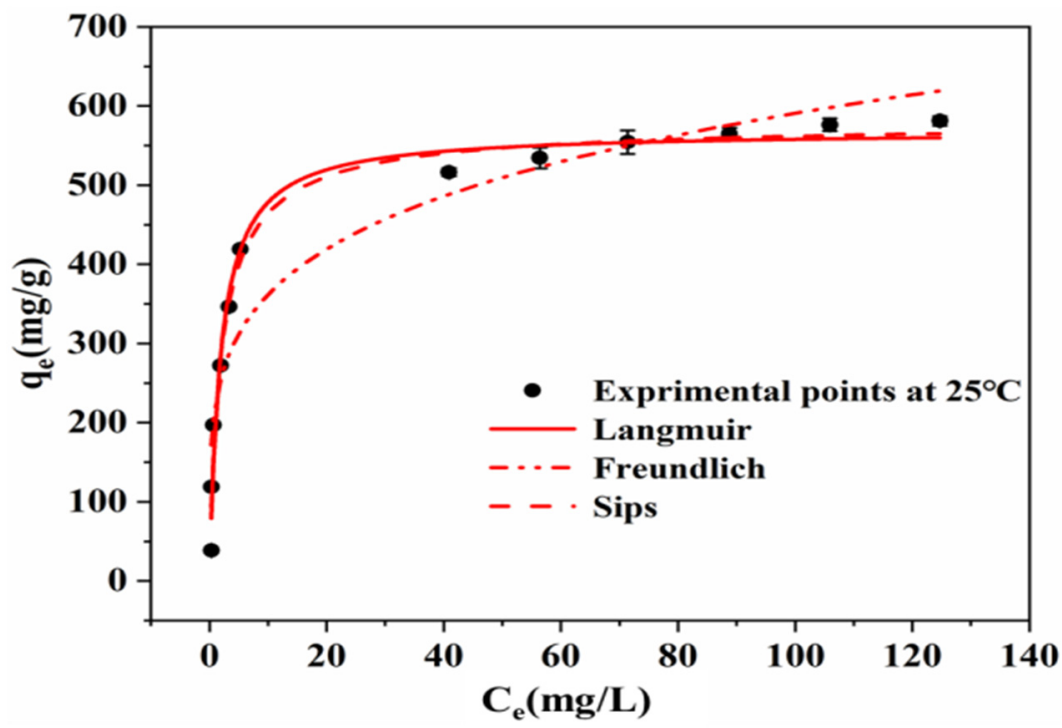

Figure 7. The experimental and the fitted isothermal adsorption curves for TC on P-POPs-3 by Langmuir, Freundlich and Sips models at $25^{\circ} \mathrm{C}$, respectively.

Table 3. Parameters obtained from the Langmuir, Freundlich, and Sips models.

\begin{tabular}{ccccccccccc}
\hline & \multicolumn{3}{c}{ Langmuir Model } & \multicolumn{3}{c}{ Freundlich Model } & \multicolumn{3}{c}{ Sips Model } \\
\hline $\begin{array}{c}\mathbf{q}_{\mathbf{m}} \\
(\mathbf{m g} / \mathbf{g})\end{array}$ & $\mathbf{k}_{\mathbf{L}}(\mathbf{L} / \mathbf{m g})$ & $\mathbf{R}^{2}$ & $\mathbf{k}_{\mathbf{F}}(\mathbf{m g} / \mathbf{g})$ & $\mathbf{n}$ & $\mathbf{R}^{2}$ & $\begin{array}{c}\mathbf{q}_{\mathbf{m}} \\
(\mathbf{m g} / \mathbf{g})\end{array}$ & $\mathbf{b}(\mathbf{L} / \mathbf{m g})$ & $\mathbf{n}$ & $\mathbf{R}^{\mathbf{2}}$ \\
\hline 568 & 0.5297 & 0.9829 & 221.3034 & 4.6906 & 0.9078 & 581 & 0.5833 & 1.1480 & 0.9850 \\
\hline
\end{tabular}

\subsection{The Effect of $p H$}

The solution $\mathrm{pH}$ was an important factor affecting the interaction between the adsorbent and the adsorbate. As shown in Figure 8a, P-POPs-3 showed an obvious pH-dependent adsorption mode for TC. Figure $8 \mathrm{~b}$ showed the zeta potential at different $\mathrm{pH}$ values, which was clear that the P-POPs-3 was positively charged in the $\mathrm{pH}$ range of $2-14$. When the $\mathrm{pH}$ of the solution was in the range of $2-8$, the adsorption capacity of TC was maintained at a high level and showed the optimal result at $\mathrm{pH} 3$, indicating that lower $\mathrm{pH}$ had a positive effect on the adsorption of TC in P-POPs-3. This phenomenon may be due to the presence of $\mathrm{TC}$ in the form of cations at $\mathrm{pH}<3.3$ [35]. Compared with $\mathrm{pH} 3$, the adsorption capacity at $\mathrm{pH} 2$ was slightly lower, which probably because the high concentration of $\mathrm{H}^{+}$leads to stronger competition at the adsorption site than electrostatic attraction. When the $\mathrm{pH}$ of the solution was in the range of $4-10$, the adsorption capacity showed a small difference and decreased compared with $\mathrm{pH}$ 3. This result may be because TC was zwitterion $\left(\mathrm{H}_{3} \mathrm{TC}\right)$ and anions $\left(\mathrm{H}_{2} \mathrm{TC}^{-}\right.$and $\left.\mathrm{HTC}^{2-}\right)$ at varying $\mathrm{pHs}$ from 3.3 to 7.7 and $\mathrm{pH}>7.7$ (Figure 8c) [36], respectively, and the addition of anions offset part of the electrostatic attraction. The significant decrease in adsorption performance at $\mathrm{pH}>10$ may be attributed to the fact that P-POPs-3 and TC molecules had the same charge, causing in electrostatic repulsion and a significant reduction in the TC adsorption capacity. As mentioned above, the variations of adsorption capacity at different $\mathrm{pH}$ indicated that the effect of electrostatic attraction was contributed to TC adsorption. In addition, there was abundant $\pi-\pi$ interaction between the benzene ring of P-POPs and the phenyl ring of TC, which drives chemical adsorption. Therefore, electrostatic attraction and $\pi-\pi$ interaction mainly favor the efficient adsorption of TC. 

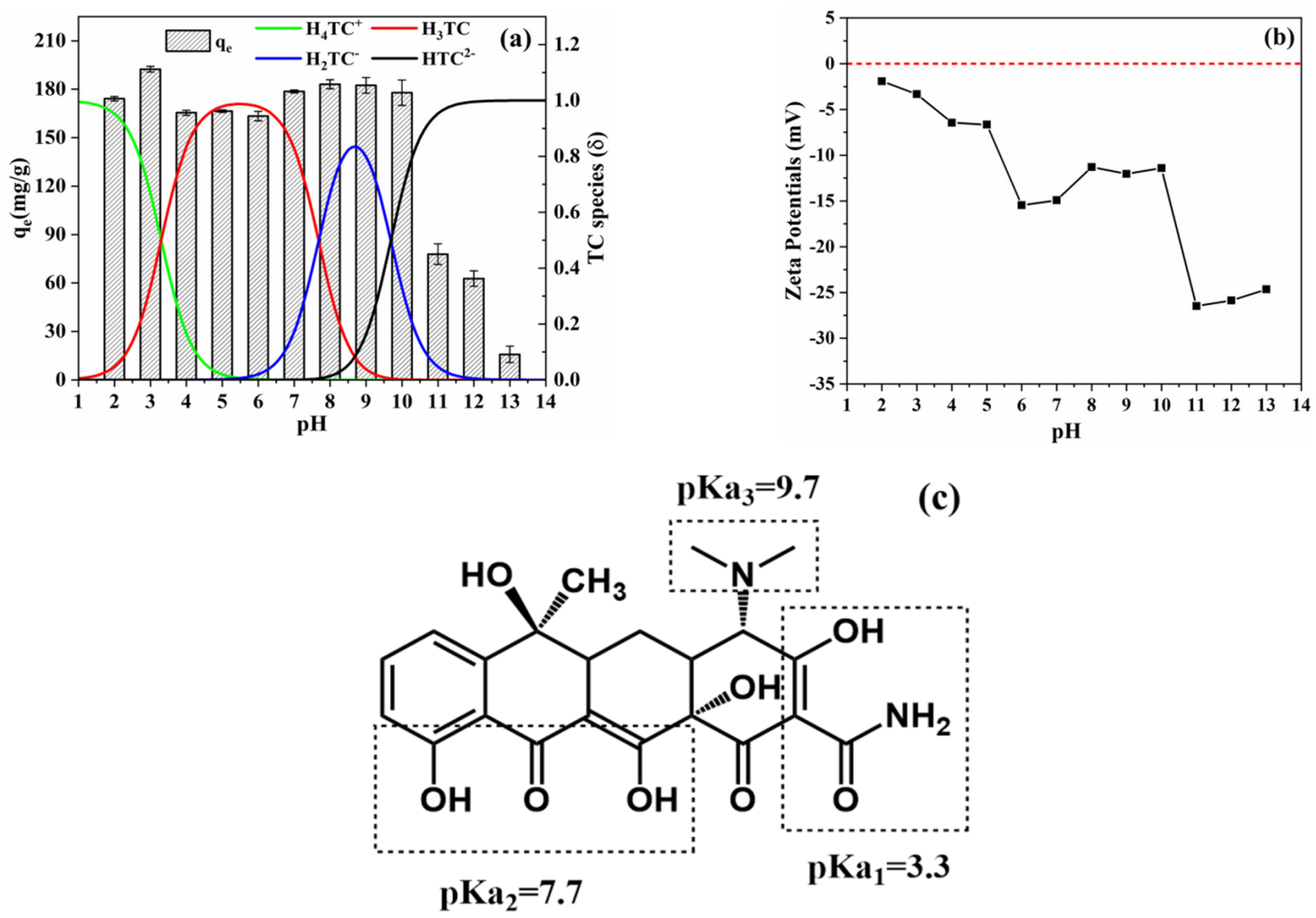

Figure 8. (a) The pH effect on TC adsorption, (b) zeta potential of P-POPs-3 and (c) the molecule structure and ionization constants of TC.

\subsection{Reused of the Adsorbents}

To evaluate the stability and reusability of P-POPs-3, (P-POPs-3)-TC was desorbed by $0.2 \mathrm{M} \mathrm{NaOH}$ solution, which was based on the weak correlation with TC adsorption under alkaline conditions. After three times of adsorption-desorption cycles, the performance of the regenerated adsorbent did not show a significant change (the adsorption capacities are 196, 195, and $194 \mathrm{mg} / \mathrm{g}$, respectively.) (Figure 9a). In the further cycles, the adsorption efficiency exhibited a slight drop, but fortunately, the adsorption capacity could still reach $176 \mathrm{mg} / \mathrm{g}(88 \%)$ after five cycles, which proved the excellent regeneration of P-POPs-3 in removing TC from the aqueous solution. To further support the result, the recycled P-POPs-3 was detected by FT-IR and shown in Figure 9b. Obviously, the characteristic peaks of the recycled P-POPs-3 were almost the same as the fresh adsorbent, and no obvious structural change was occurred during the process of adsorption and desorption, further indicating that the P-POPs were highly stable and excellently recyclable. 

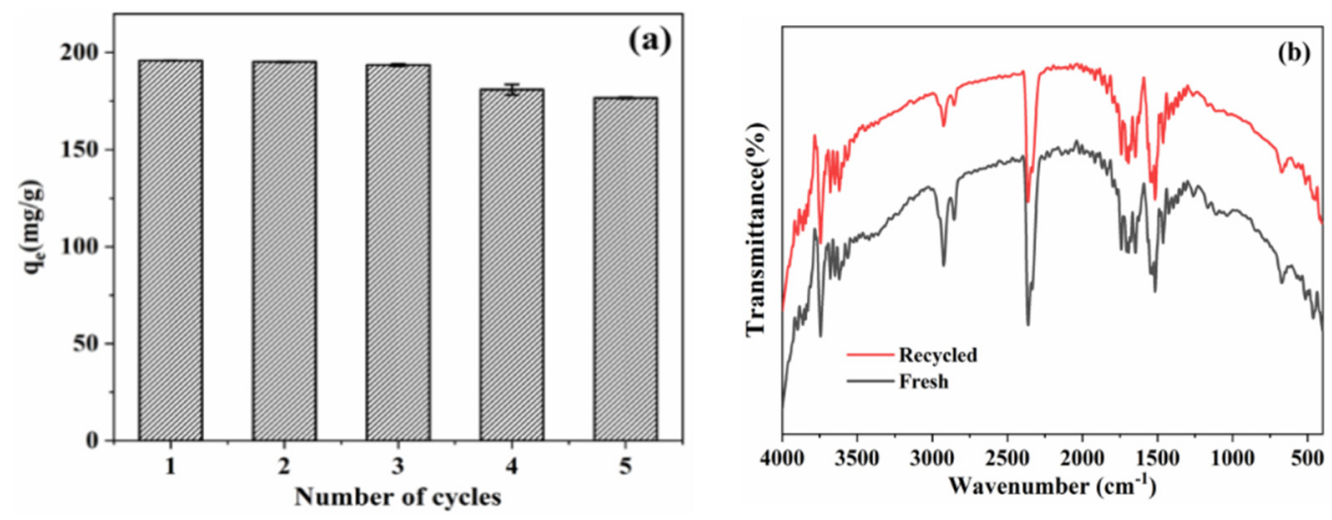

Figure 9. (a) The reusability of the P-POPs for the removal of TC and (b) FT-IR spectra of the recycled P-POPs-3.

\section{Conclusions}

In conclusion, a series of novel phenyl porous organic polymers with excellent adsorption properties were prepared through the $\mathrm{AlCl}_{3}$-catalyzed one-pot polymerization. The morphology, structure, and stability of as-prepared P-POPs were studied by different characterization testing technologies. In particular, abundant phenyl-containing functional groups, large specific surface area $\left(1098 \mathrm{~m}^{2} / \mathrm{g}\right)$ with abundant microporous structure, high pore volume $\left(0.579 \mathrm{~cm}^{3} / \mathrm{g}\right)$ made it exhibit favorable adsorption performance to the bulky TC molecule. The adsorption equilibrium was achieved within $60 \mathrm{~min}$, the removal rate of TC $(50 \mathrm{mg} / \mathrm{L})$ could reach $98 \%$, and the corresponding adsorption capacity was $196 \mathrm{mg} / \mathrm{g}$. Moreover, the highly efficient TC adsorption could be achieved in a wide $\mathrm{pH}$ range (2-10) and reused at least 5 times without significant changes in structure and efficiency. We proposed that electrostatic attraction and $\pi-\pi$ interaction were responsible for the adsorption of TC onto P-POPs. Due to the outstanding structure properties, favorable adsorption ability, wide $\mathrm{pH}$ adaptability, and good reusability, P-POPs will promise great potential in removing TC pollution from aqueous solution.

Author Contributions: For this paper, W.N. formulated the research ideas and supervised the experiments. J.L., X.B., Z.X. performed the general experimentation. W.N. and J.L. wrote and edited the article. W.N. and Y.G. revised the article. All authors read, corrected, and approved the article. All authors have read and agreed to the published version of the manuscript.

Funding: This research was funded by China Postdoctoral Science Foundation funded project (2020M673440), the Education Department Fund in Shaanxi Provincial (2021JK0763), and the Basic Research Plan of Natural Science in Shaanxi Province-General Project (Youth) (2020JQ-740, 2018JQ2028).

Conflicts of Interest: There are no conflict to declare.

\section{References}

1. Zhao, R.; Ma, T.; Zhao, S.; Rong, H.; Tian, Y.; Zhu, G. Uniform and stable immobilization of metal-organic frameworks into chitosan matrix for enhanced tetracycline removal from water. Chem. Eng. J. 2020, 382, 122893. [CrossRef]

2. Yu, F.; Li, Y.; Han, S.; Ma, J. Adsorptive removal of antibiotics from aqueous solution using carbon materials. Chemosphere 2016, 153, 365-385. [CrossRef] [PubMed]

3. Oladipo, A.A.; Ifebajo, A.O. Highly efficient magnetic chicken bone biochar for removal of tetracycline and fluorescent dye from wastewater: Two-stage adsorber analysis. J. Environ. Manag. 2018, 209, 9-16. [CrossRef]

4. Liang, Y.; Pei, M.; Wang, D.; Cao, S.; Xiao, X.; Sun, B. Improvement of soil ecosystem multifunctionality by dissipating manureinduced antibiotics and resistance genes. Environ. Sci. Technol. 2017, 51, 4988-4998. [CrossRef] [PubMed]

5. Martins, A.C.; Pezoti, O.; Cazetta, A.L.; Bedin, K.C.; Yamazaki, D.A.; Bandoch, G.F.; Asefa, T.; Visentainer, J.V.; Almeida, V.C. Removal of tetracycline by $\mathrm{NaOH}$-activated carbon produced from macadamia nut shells: Kinetic and equilibrium studies. Chem. Eng. J. 2015, 260, 291-299. [CrossRef]

6. Park, K.; Kwak, I.S. Disrupting effects of antibiotic sulfathiazole on developmental process during sensitive life-cycle stage of Chironomus riparius. Chemosphere 2018, 190, 25-34. [CrossRef] 
7. Wang, T.; Pan, X.; Ben, W.; Wang, J.; Hou, P.; Qiang, Z. Adsorptive removal of antibiotics from water using magnetic ion exchange resin. J. Environ. Sci. 2017, 52, 111-117. [CrossRef]

8. Liu, Z.; Zhu, M.; Wang, Z.; Wang, H.; Deng, C.; Li, K. Effective degradation of aqueous tetracycline using a nano-TiO $2 /$ carbon $^{2}$ electrocatalytic membrane. Materials 2016, 9, 364. [CrossRef]

9. Wu, Z.; Liang, Y.; Zou, D.; Yuan, X.; Xiao, Z.; Deng, Y.; Zhou, Y.; Jiang, L.; Qin, P. Enhanced heterogeneous activation of persulfate by $\mathrm{Ni}_{\mathrm{x}} \mathrm{Co}_{3}-\mathrm{xO}_{4}$ for oxidative degradation of tetracycline and bisphenol A. J. Environ. Chem. Eng. 2020, 8, 104451. [CrossRef]

10. Nasseh, N.; Taghavi, L.; Barikbin, B.; Nasseri, M.A. Synthesis and characterizations of a novel $\mathrm{FeNi}_{3} / \mathrm{SiO}_{2} / \mathrm{CuS} \mathrm{magnetic}$ nanocomposite for photocatalytic degradation of tetracycline in simulated wastewater. J. Clean. Prod. 2018, 179, 42-54. [CrossRef]

11. Guo, F.; Huang, X.; Chen, Z.; Sun, H.; Chen, L. Prominent co-catalytic effect of CoP nanoparticles anchored on high-crystalline g- $\mathrm{C}_{3} \mathrm{~N}_{4}$ nanosheets for enhanced visible-light photocatalytic degradation of tetracycline in wastewater. Chem. Eng. J. 2020, 395, 125118. [CrossRef]

12. Mohammed, A.A.; Kareem, S.L. Adsorption of tetracycline fom wastewater by using Pistachio shell coated with $\mathrm{ZnO}$ nanoparticles: Equilibrium, kinetic and isotherm studies. Alex. Eng. J. 2019, 58, 917-928. [CrossRef]

13. Chen, G.X.; Li, H.F.; Wang, D.D.; Li, S.Q.; Fan, X.B.; Zhang, J.M. Adsorption of toxic gas molecules on pristine and transition metal doped hexagonal GaN monolayer: A first-principles study. Vacuum 2019, 165, 35-45. [CrossRef]

14. Chen, G.X.; Wang, R.X.; Wang, D.D.; Li, H.X.; Liu, S.; Zhang, J.M. First-principles study of CO and NO adsorption on pristine and transition metal doped blue phosphorene. Vacuum 2020, 179, 109503. [CrossRef]

15. Debnath, B.; Majumdar, M.; Bhowmik, M.; Bhowmik, K.L.; Debnath, A.; Roy, D.N. The effective adsorption of tetracycline onto zirconia nanoparticles synthesized by novel microbial green technology. J. Environ. Manag. 2020, 261, 110235. [CrossRef] [PubMed]

16. Cheng, D.; Ngo, H.H.; Guo, W.; Liu, Y.; Chang, S.W.; Nguyen, D.D.; Nghiem, L.D.; Zhou, J.; Ni, B. Anaerobic membrane bioreactors for antibiotic wastewater treatment: Performance and membrane fouling issues. Bioresour. Technol. 2018, 267, 714-724. [CrossRef]

17. Cao, J.; Lai, L.; Lai, B.; Yao, G.; Chen, X.; Song, L. Degradation of tetracycline by peroxymonosulfate activated with zero-valent iron: Performance, intermediates, toxicity and mechanism. Chem. Eng. J. 2019, 364, 45-56. [CrossRef]

18. Liu, Y.; Gao, Y.; Yao, B.; Zou, D. Removal of chlortetracycline by nano-micro-electrolysis materials: Application and mechanism. Chemosphere 2020, 238, 124543. [CrossRef] [PubMed]

19. Gao, Y.; Li, Y.; Zhang, L.; Huang, H.; Hu, J.; Shah, S.M.; Su, X. Adsorption and removal of tetracycline antibiotics from aqueous solution by graphene oxide. J. Colloid. Interf. Sci. 2012, 368, 540-546. [CrossRef]

20. Song, Z.; Ma, Y.L.; Li, C.E. The residual tetracycline in pharmaceutical wastewater was effectively removed by using $\mathrm{MnO} 2$ /graphene nanocomposite. Sci. Total Environ. 2019, 651, 580-590. [CrossRef]

21. Yang, J.; Dou, Y.; Yang, H.; Wang, D. A novel porous carbon derived from $\mathrm{CO}_{2}$ for high-efficient tetracycline adsorption: Behavior and mechanism. Appl. Surf. Sci. 2021, 538, 148110. [CrossRef]

22. Chang, P.H.; Li, Z.; Jean, J.S.; Jiang, W.T.; Wang, C.J.; Lin, K.H. Adsorption of tetracycline on 2:1 layered non-swelling clay mineral illite. Appl. Clay Sci. 2012, 67, 158-163. [CrossRef]

23. Miao, J.; Wang, F.; Chen, Y.; Zhu, Y.; Zhou, Y.; Zhang, S. The adsorption performance of tetracyclines on magnetic graphene oxide: A novel antibiotics absorbent. Appl. Surf. Sci. 2019, 475, 549-558. [CrossRef]

24. Zhou, J.; Ma, F.; Guo, H. Adsorption behavior of tetracycline from aqueous solution on ferroferric oxide nanoparticles assisted powdered activated carbon. Chem. Eng. J. 2020, 384, 123290. [CrossRef]

25. Zhou, Y.; Yang, Q.; Zhang, D.; Gan, N.; Li, Q.; Cuan, J. Detection and removal of antibiotic tetracycline in water with a highly stable luminescent MOF. Sens. Actuators B Chem. 2018, 262, 137-143. [CrossRef]

26. Liu, P.; Liu, W.J.; Jiang, H.; Chen, J.J.; Li, W.W.; Yu, H.Q. Modification of bio-char derived from fast pyrolysis of biomass and its application in removal of tetracycline from aqueous solution. Bioresour. Technol. 2012, 121, 235-240. [CrossRef] [PubMed]

27. Ahamad, T.; Chaudhary, A.A.; Naushad, M.; Alshehri, S.M. Fabrication of $\mathrm{MnFe}_{2} \mathrm{O}_{4}$ nanoparticles embedded chitosandiphenylureaformaldehyde resin for the removal of tetracycline from aqueous solution. Int. J. Biol. Macromol. 2019, 134, 180-188. [CrossRef]

28. Zhang, Y.; Riduan, S.N. Functional porous organic polymers for heterogeneous catalysis. Chem. Soc. Rev. 2012, 41, 2083-2094. [CrossRef]

29. Sun, Q.; Dai, Z.; Liu, X.; Sheng, N.; Deng, F.; Meng, X.; Xiao, F.S. Highly efficient heterogeneous hydroformylation over Rhmetalated porous organic polymers: Synergistic effect of high ligand concentration and flexible framework. J. Am. Chem. Soc. 2015, 137, 5204-5209. [CrossRef]

30. Ji, G.; Yang, Z.; Yu, X.; Zhao, Y.; Zhang, F.; Liu, Z. Photosensitive Hyper-Cross-Linked Polymers Derived from Three-Dimensional Ringlike Arenes: Promising Catalysts for Singlet-Oxygen Generation. ACS. Sustain. Chem. Eng. 2020, 8, 16320-16326. [CrossRef]

31. Zhang, S.; Li, Y.; Shi, C.; Guo, F.; He, C.; Cao, Z.; Hu, J.; Cui, C.; Liu, H. Induced-fit adsorption of diol-based porous organic polymers for tetracycline removal. Chemosphere 2018, 212, 937-945. [CrossRef] [PubMed]

32. Wang, S.; Hu, Q.; Liu, Y.; Meng, X.; Ye, Y.; Liu, X.; Song, X.; Liang, Z. Multifunctional conjugated microporous polymers with pyridine unit for efficient iodine sequestration, exceptional tetracycline sensing and removal. J. Hazard. Mater. 2020, $387,121949$. [CrossRef] [PubMed] 
33. Choi, Y.K.; Choi, T.R.; Gurav, R.; Bhatia, S.K.; Park, Y.L.; Kim, H.J.; Kan, E.; Yang, Y.H. Adsorption behavior of tetracycline onto Spirulina sp.(microalgae)-derived biochars produced at different temperatures. Sci. Total Environ. 2020, 710, 136282. [CrossRef] [PubMed]

34. Rozyyev, V.; Thirion, D.; Ullah, R.; Lee, J.; Jung, M.; Oh, H.; Atilhan, M.; Yavuz, C.T. High-capacity methane storage in flexible alkane-linked porous aromatic network polymers. Nat. Energy 2019, 4, 604-611. [CrossRef]

35. Geng, T.; Zhang, W.; Zhu, Z.; Chen, G.; Ma, L.; Ye, S.; Niu, Q. A covalent triazine-based framework from tetraphenylthiophene and 2, 4, 6-trichloro-1, 3, 5-triazine motifs for sensing o-nitrophenol and effective $\mathrm{I}_{2}$ uptake. Polym. Chem. 2018, 9, 777-784. [CrossRef]

36. Gu, C.; Karthikeyan, K. Interaction of tetracycline with aluminum and iron hydrous oxides. Environ. Sci. Technol. 2005, 39, 2660-2667. [CrossRef] 